\title{
Judith Josephson. “Ohrmazd's plan for creation according to Book Three of the Dēnkard"
}

\section{Samra Azarnouche}

\section{(2) OpenEdition}

1 Journals

\section{Édition électronique}

URL : http://journals.openedition.org/abstractairanica/43530

DOI : 10.4000/abstractairanica.43530

ISBN : 1961-960X

ISSN : 1961-960X

\section{Éditeur :}

CNRS (UMR 7528 Mondes iraniens et indiens), Éditions de l'IFRI

Référence électronique

Samra Azarnouche, « Judith Josephson. "Ohrmazd's plan for creation according to Book Three of the Dēnkard" », Abstracta Iranica [En ligne], Volume 37-38-39 | 2018, document 3, mis en ligne le 30 décembre 2018, consulté le 02 octobre 2020. URL : http://journals.openedition.org/abstractairanica/ 43530 ; DOI : https://doi.org/10.4000/abstractairanica.43530

Ce document a été généré automatiquement le 2 octobre 2020.

Tous droits réservés 


\title{
Judith Josephson. “Ohrmazd's plan for creation according to Book Three of the Dēnkard"
}

\author{
Samra Azarnouche
}

\section{RÉFÉRENCE}

Judith Josephson. "Ohrmazd's plan for creation according to Book Three of the Dēnkard" in A. Krasnowolska, R. Rusek-Kowalska (eds.). Studies on the lranian World I: Before Islam. Proceedings of the 7th European Conference of Iranian Studies (Crakow 2011), Krakow: Jagellonian University Press, 2015, p. 153-161.

1 Menant une réflexion originale sur la structure du Dēnkard III, l'A. fait l'hypothèse d'une division tripartite, dont la première partie définit les concepts selon les principes de la logique, la seconde les met en rapport avec la vie de l'homme dans le monde matériel et la troisième développe leurs différentes applications. Deux principes cosmogoniques sont ici choisis pour servir de fil conducteur à travers les trois sections : xwarrah, à prendre plutôt dans le sens technique du rôle imparti à chacun et qui définit son attitude dans le monde matériel, et handāzišn, qui se réfère au programme divin dont l'ultime aboutissement est la Rénovation (frašgird). Cette présentation progressive permettait au lecteur du Dēnkard III de s'imprégner, pas à pas, de l'idéologie zoroastrienne. 


\section{AUTEURS}

\section{SAMRA AZARNOUCHE}

EPHE, Mondes iranien et indien, Paris 